\title{
Social Networking Websites as an Innovative Framework for Connectivism
}

\author{
Hasan Tinmaz \\ Istanbul Kultur University, Turkey
}

\begin{abstract}
With the Internet's innate structure, new generations have increased their abilities on finding new people whom they have something in common and networking with them. Web 2.0 technologies have altered the ways how new generations manage their learning activities. Many studies showed that most of the social networking websites have created different learning networks and online communities on their bodies. As a result, many educational institutions have taken advantages of social networking websites for maintaining their teaching and learning activities. On the other hand, institutions suffer from the deficiency of guiding learning theories and their effective implementation. This article discusses Connectivism as an alternative platform for instructional processes on social networking websites. Connectivism explains learning in terms of interactions on a network where the learners exchange their knowledge. Social networking websites which offer connections in the form of friendships provide a context for the implementation of Connectivism. Therefore, the article aims to depict a relationship between educational activities on social networking websites and the contemporary Connectivist Learning Theory. The article also presents suggestions on integration of social networking websites' into education.
\end{abstract}

Keywords: Connectivism; Social Networking Websites, Facebook, Web 2.0

\section{Introduction}

Learning could take place in anywhere and at anytime; in the family, in hobbies, at work, in a community etc. (Siemens \& Tittenberger, 2009). Yet, in the traditional learning process, it is vital that students absorb what their instructors tell them. The learners of the last two decades have learned differently than the earlier generations did. They have both followed formal and informal ways to extend their cognitive schemata.

Social part of human has usually been neglected in the learning process. On the other hand, today's active learners demand more on socialization which put pressure on instructors to implement more group activities or simulation-based activities (Palloff \& Pratt, 2007). In parallel, the current situation has triggered educational scientists to search for new learning theories (McWilliam \& Haukka, 2008) which aim to explain the dynamics of the most recent teaching and learning and processes.

As an alternative theory, Connectivism tries to describe learning as a construct in a highly networked digital era. According to Siemens and Tittenberger (2009), Connectivism refers to 
the view that "knowledge and cognition are distributed across networks of people and technology, and learning is the process of connecting, growing, and navigating those networks" (p.11). Baggaley (2012) recapitulates the Connectivism literature and concludes that Connectivism is an appropriate theory for depicting the recent need for re-evaluating the asynchronous instructional methods. Basically, Connectivism suggests that teachers and students who share an online platform should interact more directly and more frequently.

It is clear that in this century, there is a great deal of knowledge that a single person can never absorb. Similarly, knowledge is altering rapidly than it was in previous centuries. These two realities unfolded two essential conclusions: (1) one single person cannot know everything and (2) a person must update himself/herself as the knowledge changes (Tracey, 2009). The new century has been furnished with Web 2.0 technologies so that a person can follow the changes in knowledge and can learn the most updated version of knowledge. The role of Web 2.0 technologies is to provide a network of people who connect to each other wherever and whenever they need information.

Among these Web 2.0 technologies, social networking websites are the most popular entities where billions of people register and utilize for fulfilling their need of communication, socialization, participating common interest groups and so forth. Many people refer to the definition of Boyd and Ellison (2007) for social networking websites as;

Web-based services that allow individuals to (1) construct a public or semi-public profile within a bounded system, (2) articulate a list of other users with whom they share a connection, and (3) view and traverse their list of connections and those made by others within the system. The nature and nomenclature of these connections may vary from site to site.

The social networking web sites are one of latest developments on the Internet regarding to human socialization and communication. People utilize the social networking web sites for interacting and communicating with other people from all over the world. As a trend, people are registering to these web sites and creating communities with a variety of similar interests. The users of social networking websites can share their photos, videos, upcoming events, and notes with other users on the web.

Among the entire population who uses the Internet on the world, $75 \%$ is the member of social networking websites. This accounts for $10 \%$ of the time which people spend on the Internet in entire world (Global faces and networked places, 2011). Hence, in a socially networked society, the role of education has been changed for the whole citizens, especially the youth. In that sense, new version of educational actions must address the issues not only related with preparation of youth to prospective occupations but also preparation to active participation in their communities ("Living and learning with,", 2008).

As the definition implies, social networking websites are built on the existence of various connections/relationships among people. Among many social networking websites, the established relationships could be named with different tags; friends, contacts, followers, or fans (Boyd \& Ellison, 2007). Furthermore, there is an infinite opportunity to find new people, new information, new contacts and new networks on social networking websites (Donath, 2008). Besides, social networking websites assist people to keep their already existing contacts and to create new connections (Ellison, Steinfield, \& Lampe, 2007). In brief, the social 
networking websites are powerful tools in terms of offering and maintaining connections among people.

Connectivism specifically emphasizes on learning networks and their established connections among members. According to Connectivist learning theory, the learning will occur as the learners keep the tracks of their questions on their networks where they gain knowledge from different nodes and the members of learning networks (Guder, 2010). Therefore, the number of connections is essential for the occurrence of knowledge acquisition process.

It seems that social networking websites' connection-offered structures could provide a new platform for comprehending and implementing the Connectivist learning theory. In order to take advantage of new premises regarding with Connectivism, Facebook which is the most well-known social networking website of our time, could certainly recommend a field of implementation where billions of people attached to each other in its highly networked body.

From the first days of its delivery on the Internet, Facebook has changed its structure in terms of its services and its visual design. Some Facebook functions have remained the same since the beginning and raised Facebook among the rank of well-branded social networking websites in the world. Facebook provided many opportunities to identify new connections via its profile features. For instance, Facebook's profile information including name, one photo, gender, birthday, and certain contact information serves as a platform for identifying similar demographics connecting to each other.

The second building block of Facebook is the extension of the basic personal descriptions such as family members, city, place of birth, religion, favorite authors and books, or schools graduated. It is also clear that the Facebook members tend to establish new connections, for instance, with the family relatives, the believer of the same religion, the ex-classmates and so forth by considering this broad profile information. As the third element of Facebook profiles, the Facebook members could reconcile high-order connections with the features of Friends, Groups and Fans.

Human learning should be supported by technologies for increasing effectiveness (Siemens, 2006). Thus, researchers must continue their scientific studies for determining alternative systems which could bring benefits to educational framework (Muñoz \& Towner, 2009). Furthermore, current researchers must conduct more studies on understanding who are using social networking websites and for what reasons they utilize them.

This article summarizes the Connectivism as a new learning theory and its utilization in the social networking website platforms and offers implications and suggestions for instruction. Overall, this paper contributes to the existing literature by examining in a more comprehensive way about the process of social networking website integration into education while taking advantage of Connectivism as the main theory of learning.

\section{The Connectivism as an Innovative Definition of Learning}

During the last decade, students have been evolved from passive knowledge absorbers to the active participants of their personal learning journeys. Their new roles guide them to seek their personal knowledge and meanings within a framework of their distinctive and personal 
experiences (Tracey, 2009). This new situation has altered the definitions of instructional processes, especially learning. Many authors have highlighted the significance of adjusting the learning theories in accordance with the necessities of the current digital era (Bell, 2011; Boitshwarelo, 2011; Kerr, 2007; Mattar, 2010; McWilliam \& Haukka, 2008; Ravenscroft, 2011).

Bell (2011) argues that Connectivism has broader scope than other learning theories, such as behaviorism or constructivism. Moreover, Bell remarks that Connectivism, which emphasizes the importance of learning networks, is also "a network theory of learning" (p.103) situated on different epistemologies.

It is clear that in Connectivist learning theory, people establish knowledge networks which work like an updating mechanism for newer content. Moreover, since the cognitive load is distributed to different points on network, a person could move to upper stages of thinking, reasoning, and learning (Siemens, 2006). Mattar (2010) points out that distribution of the cognitive load as a result of learning process could be shared among other people and different technologies. Therefore, more effective and productive learning could happen as a result of having less cognitive load on a person. Additionally, the Connectivist learning theory could aim higher levels of learning such as synthesizing and evaluation. In order to realize those higher levels of learning, new technological tools such as blogs and social networking web sites, offer new opportunities (Rousseau, 2007).

Connectivism defines a new concept; hubs, meaning to strongly associated people on a social network who have the ability to promote and sustain the knowledge streaming from one point to another (Siemens, 2004a). For example, in terms of Facebook, as a social networking website, more experienced users might be a hub where they can control instructional activities on Facebook.

Boitshwarelo (2011) discloses five characteristics of Connectivism that; (a) the learner is a part of a community who not only utilizes the community but also contribute to that community, (b) the community is a joint point of many independent networks which are connected to each other for knowledge creation purposes, (c) the knowledge has been distributed on networks and among members' of these networks, (d) information is continuously changing where a person must assess its precision, and (e) the knowledge does not belong to one single discipline, whereas knowledge creation require cooperation of many disciplines. These five points could easily be associated with the innate features of social networking websites where the members could join different groups in terms of creating new communities and networks and could supply themselves with incoming knowledge from different connections of diverse subject matter areas.

Instructional designers should pay attention to the fundamental characteristics of Connectivism in terms of its central design elements; the person, the social interactions and networked communities. For example, Connectivist teachers assist their learners to alter their existing knowledge while facilitating the learners to move beyond their knowledge by establishing connections to other people (Starkey, 2010).

\section{Utilization of Connectivism into Social Networking Websites}


Dede (2008) states that Web 2.0 technologies altered the definition, processes, and members of learning action. Web 2.0 technologies have disseminated newer tools into the Internet context and altered the creator of the knowledge accordingly. Moreover, around different Web 2.0 tools, many online communities have been established easily and practiced on creation of knowledge. As a result, Dede (2008) concludes that Web 2.0 technologies provided a shift in epistemology of learning. In that sense, Connectivism offers premises for better education via social networking websites. For example; social networking websites will play more important roles in providing new connections for the people (Ravenscroft, 2011).

Connectivism inquires about the general impact of established networks and human complexities on learning (Siemens, 2004b). In a Connectivist point of view, one piece of information might be accurate for today, whereas with some changes might be erroneous in the future (Williams M., 2008). Therefore, on established networks, people could update their knowledge with the help of connected bodies. For instance; certain learning communities, such as classrooms in a school, might connect to other related learning communities so that networks might bring more advantage to the learners (Williams, 2008). Memberships to different social networking websites and joining to different groups in the forms of learning communities, could offer learning opportunities in the form of online formal or non-formal classrooms.

As Mattar (2010) points out learning is not a sole individual knowledge digesting process, learning needs interaction. Learning occurs as a result of utilizing outside sources (other people, online databases, blogs, and etc...) and establishing connections between the individual and the outside sources. Furthermore, Williams $(2008$, p.5) offers teachers and learners to use Connectivist perspective to keep themselves updated on latest developments in any kind information where the pace of information streaming is unpredictably high in the last digital decades. From a Connectivist point of view, in order for knowledge to be transferred as a permanent learning, knowledge must be associated with "the right people in the right context" (Siemens, 2004b).

Kop and Hill (2008) acknowledge the possible advantages of Web 2.0 technologies and their mobile utilizations in term of providing new instructional framework for adapting Connectivism. Both offline and online social networks will supply the required information for the connected entities in the form of identifying right hubs and connections. Moreover, Connectivist approach will realize the dream of centralizing the learner in the juxtaposition of all other elements. Therefore, Kop and Hill (2008) emphasize that the learners will gain independence of deciding the content, the message, the media, and all other elements they want to utilize.

For instructional context, content is something which learners consume cognitively. On the other hand, the content must be re-created or co-created by learners in a networking context (Siemens \& Tittenberger, 2009). Social networking websites could offer many opportunities with their tools, for the creation of new knowledge and making alterations whenever it is needed. The stakeholders who are joined to any social networking websites could play the role of knowledge creation facilitator by providing necessary inputs to the process.

Siemens (2006) states that "our mind is a network... an ecology where individual points of knowledge are distributed across the entire entity..." (p.4). Connectivism values the network's storage capability in terms of holding developed information. Besides, learners might use this 
capability to upload and download the information into their own systems (Williams, 2008). From that perspective, for instance, Facebook offers its members to the chance of uploading and downloading what kind of information they want to see in their personal networks.

The Connectivist theory has demonstrated that on a connected network, learners increase their capacities, performances, and levels of knowledge while creating and reforming the information. In that sense, social networking websites comprising already linked members in their innate technologies have a superior potential to enrich learners' current knowledge, skills, and abilities. Connectivism could assist different researchers to explain the underlying reasons of change in the learners' current situation as a result of their interaction on social networking websites. The theory of Connectivism enlightened that social networking websites, as the platforms for simply establishing and maintaining personal and professional networks, could improve instructional processes for both learners and educators.

Williams, Karousou and Mackness (2011) point out that many universities are impressively advertising themselves on their Web 2.0 contexts; such as Twitter accounts, Facebook pages, and Skype names. On the other hand, they still become out of date since they do not attempt to take advantage of these contexts for their educational activities. This situation will be a flawed approach for academicians where their learners are mostly registered to different social networking websites and using a variety of different mobile technologies for accessing their accounts all the time.

Many Web 2.0 tools (blogs, wikis, social networking websites, and RSS feeds) allow their users to access easily to current knowledge about anything which fulfills the basic premises of the Connectivist learning theory. On the other hand, the users must know about assessing these sources on Web 2.0 technologies to enhance its current knowledge and network which assist to organize that knowledge (Guder, 2010). Therefore, it is essential to inform both learners and instructors about the utilization of social networking websites within the Connectivist learning theory framework.

\section{Implications and Suggestions for Connectivism within Social Networking Websites}

Starkey (2010) reveals that teachers want to use different Web 2.0 technologies (especially Facebook as a social networking website) in their classrooms while realizing their benefits for teaching and learning activities. On the other hand, the teachers suffer from the lack of guidance of learning theories and their implications.

Connectivism is a relatively new theory of learning where scholars are conducting research in order to realize its implications for the field of education. Social networking websites are also comparatively new tools as instructional platforms. Therefore, these two innovative concepts require more elaboration for comprehending their effects for educational processes. For example, Tu, Sujo-Montes, Yen, Chan, and Blocher (2012) assert that there is "... a lack of understanding of the social networking learning paradigm and inappropriate integration" (p.13). This section encapsulates examples from education field and suggestions for educational stakeholders for taking advantage of both Connectivism and Social Networking Websites in their platforms. 
One of the latest studies has been conducted by Tu, Sujo-Montes, Yen, Chan, and Blocher (2012) where they settle a case study with a pilot online course which was built on different Web 2.0 tools and stem from Connectivism and Personal Learning Environment (PLE). Mainly, the researchers assisted the learners to create connections between each other which facilitate the learners to attain knowledge resulting in more learning. As a result of threesemester-long practices, the researchers reveal their conclusions that "the course makes their learning more personal, connective, social, networking, and open” (p.17).

Tu, Sujo-Montes, Yen, Chan, and Blocher (2012) demonstrated some examples of using social networking websites in a Connectivism-based course. For example, they created discussions on a social networking website and the learners expressed their ideas and knowledge freely. Whenever the students need guidance, a more experienced person (the concept of hub in Connectivism) facilitated the group. Tu, et al. (2012) stated that this social networking design assisted the students to create their authentic learning community which offered context-rich social interactions for them. Moreover, the students with mobile technologies more actively engaged in their learning progress and took advantage of various learning opportunities wherever and whenever available or possible. The course instructors also commented that their students become more digital citizens who are capable of creating and sharing the content. In short, instructors/teachers could organize discussions on social networking websites where they will be the hub for the rest of the student connections. This study also shows that instructional designers should take advantage of other Web 2.0 tools within the Connectivist perspective.

Tracey (2009) unfolds alternative Web 2.0 technologies for learners' personal learning networks; social bookmarks, news feeds, podcasts, blogs, wikis, discussion forums, social networking websites (especially Facebook), and microblogging (especially Twitter). From the usage statistics, particularly Facebook has the most crowded number of users on its system. Thus, it provides a well-established platform for creating connections among users who have different knowledge levels on any topic. In that manner, it is essential to furnish all instructional stakeholders with the necessary knowledge on identifying, establishing, and maintaining the personal contacts as their knowledge creator bodies. The instructors could create task-oriented or topic-surrounded learning communities where each learner will be a part of that community who not only utilizes the community but also contribute to that community. Moreover, by using social network analysis, the teachers could realize the central students, the density of the discussions (which shows an added-value of instructional process inferring from the principle of "connecting entities") and social connection maps which could yield more information about the learning communities inside of the courses.

Thomas (2010) noted that Facebook creates opportunities for establishing new contacts and joining to different networks and communities. Thomas (2010) bears a resemblance to Facebook contacts with the switching of business cards or any other contact information papers. Therefore, Facebook groups which are set up around certain learning objectives will provide a platform toward creation or adaptation of knowledge cooperatively. Likewise, Sims (2008) pointed out that Facebook could provide connections among people for forming communities of practice. Moreover, Facebook will provide a flexible context for the learners to cooperate with the connected people. The instructional designers should take advantage of existing Facebook groups and applications for designing their instruction starting from setting learning objectives together. The instructors should offer their learners the ways of building 
their social presence by using social networking websites that facilitate group discussion to build and support their learning by creating a sense of belongingness (Cook, 2012).

Wan, Mohd, Zinatul, Wan and Noor (2012) point out that social networking websites have a potential of being used a knowledge management bodies within a Connectivist perspective. Wan et al. (2012) note that social networking website use in the classroom promotes the processes of cooperation, collaboration, trust, and sharing. In that sense, the instructional designers should integrate social networking websites whenever they need a knowledge system in their instructional contexts.

Siemens (2006) pointed that 'Know where' and 'know who' is more important today than knowing what and how" (p.32). In that manner, the learners and instructors of the current era must learn about how to dig into an endless bunch of knowledge. They can enhance and manage their abilities and skills in creating their own personal learning environment through connected points and established hubs. It is clear that current era demands multidisciplinary approaches to comprehending different phenomenon around us. As Cook (2012) stated new technologies, especially Web 2.0, are assisting individuals establishing connections of information from different subject matter areas which lead depth and breadth in personal knowledge. Thus, the instructors should utilize social networking websites for accessing different subject matter experts, as hubs on the networks, and inform their students on how to get benefits of these connections on the networks.

The role of instructors must change while using Connectivist principles on social networking websites. As Fonseca (2011) noted, the teacher role as the final decision maker throughout the instructional processes, should be altered to a co-learner. In that sense, teachers should learn more about their current roles within the new framework. Their new roles do not refer to the passive observers of the processes but rather more active connection point of the social network. That perception change or epistemological shift will not be easily managed by the instructors. Hence, the institutions which are responsible for training instructors in different organizations must develop new curriculum and examples for their learners who will be the prospective teachers of the system. It is also vital to take advantage of Connectivist principles and Social Networking Websites while training the early adapters of the innovations.

\section{Drawbacks of Connectivism within Social Networking Websites}

There are some problematic issues for applying the Connectivist theory into social networking websites. For instance, Starkey (2010) considers Connectivism as a theory for technologically developed societies. Fonseca (2011) argues that most of the teachers from underdeveloped or developing countries do not have their personal computers, especially laptops. In other words, the successful applications of Connectivism on social networking websites require a certain investment on technology. Moreover, in some cases, technological background cannot guarantee that learning will occur. For example, the biggest mistake in applying Connectivism for social networking websites could be counting the frequencies of interactions and making inferences accordingly. In other words, the number of interactions among connected people does not directly refer to the amount of learning (Williams, Karousou, \& Mackness, 2011).

Additionally, various studies generally suggest that even in technology-rich environments, the equipment is often ignored or used in a cursory way. Technology equipment does not 
necessarily assume technology integration. Nor does technology inherently provide access to these Connectivist resources. Unfortunately, most K-12 schools ban the use of social networking websites in their technology-rich buildings. Similarly, the media is full of stories about employers firing workers based on their social networking website uses. Thus, it is not easy to assume that current societies will buy into these practices. Nevertheless, we need implementation strategies and success stories.

Cook (2012) asserts that the students must be self-directed learners for applying Connectivism in the courses. Thus, the students must understand the need for new knowledge to be learnt. Cook (2012) suggests deeper connections between students and teachers in their classrooms so that the students attain more permanent and effective knowledge. Therefore, while applying the Connectivist perspective on any social networking website, the instructors must pay attention to the learner characteristics, especially self-directedness.

This article assumes that the established networks will yield meaningful information. The literature also states that may not be the case. One problem with the Internet today (arguably the largest social networking websites) is the amount of irrelevant, inaccurate, and inherently biased information available instantaneously. Although social networking websites like Facebook and Linkedln allow users to select their contacts, these associations may not lead to knowledge acquisition. Social networking website users must still determine the credibility, relevance, accuracy, and authority of author information when they receive it from their network. Thus, instructors must know how to promote information literacy in these contexts so that the users could evaluate the quality and meaningfulness of the information to the social networking websites. McBride (2012) remarks that Connectivism is one of the best approaches to teach about information literacy. Therefore, learners could furnish themselves with the information literacy while adapting themselves into Connectivist learning contexts.

Kerr (2007) offers that premises and practices of Connectivism must be re-visited and should be further developed. In this regard, this article is a single attempt for creating awareness on possible bridges between the two innovations of our time; Connectivism as a learning theory, and Social Networking Websites as a platform for effectively taking advantage of its premises. Bell (2011) summarizes the entire situation as; "Technology brings golden opportunities but can leave a trail of disappointment; good research and evaluation can contribute to a world in which we learn from our mistakes and maximize our future opportunities" (p.113).

This article presents and introduces a new perspective of integrating social networking websites using Connectivism as an instructional strategy. The article suggests that there is a strong need for further research on the implications of Connectivism. Further research using the suggestions and implications of this study will help provide more understanding about the instructional utilization. This article argues that more research needs to be done for realizing the effects of social networking use with the guidance of Connectivism.

\section{References}

Baggaley, J. (2012).Thesis and antithesis. Distance Education, 33(1), 117-123. 
Bell, F. (2011). Connectivism: Its place in theory-informed research and innovation in technology-enabled learning. International Review of Research in Open and Distance Learning, 12(3), 98-118.

Boitshwarelo, B. (2011). Proposing an integrated research framework for connectivism: Utilising theoretical synergies. International Review of Research in Open and Distance Learning, 12(3), 161-179.

Boyd, D. M. \& Ellison, N. B. (2007). Social network sites: Definition, history, and scholarship. Journal of Computer-Mediated Communication, 13(1). Retrieved on 11 May 2008 from http://jcmc.indiana.edu/vol13/issue1/boyd.ellison.html

Cook, V. (2012).Learning everywhere, all the time. The Delta Kappa Gamma Bulletin, Spring, 48-51.

Dede, C. (2008, May/June). A seismic shift in epistemology. EDUCAUSE Review, 43(3), 80-81.

Donath, J. (2008). Signals in social supernets. Journal of Computer-Mediated Communication, 13, 231-251.

Ellison, N. B., Steinfield, C., \& Lampe, C. (2007). The benefits of Facebook "friends": Social capital and college students' use of online social network sites. Journal of Computer-Mediated Communication, 12(4), 1143-1168.

Fonseca, D. E. L. (2011). EduCamp Colombia: Social networked learning for teacher training. International Review of Research in Open and Distance Learning, 12(3), 60-79.

Global faces and networked places (2011, March). A Nielsen report on social networking's new global footprint. Retrieved on 15 October 2011 from http://blog.nielsen.com/ nielsenwire/ wp-content/uploads/2009/03/ nielsen_globalfaces_mar11.pdf

Guder, C. (2010). Patrons and pedagogy: A look at the theory of connectivism. Public Services Quarterly, 6, 36-42.

Kerr, B. (2007, February). A challenge to connectivism. Transcript of Keynote Speech, Online Connectivism Conference. University of Manitoba. Retrieved from http://Itc.umanitoba.ca/wiki/index.php?title=Kerr_Presentation

Kop, R. \& Hill, A. (2008). Connectivism: Learning theory of the future or vestige of the past?. International Review of Research in Open and Distance Learning, 9(3), 1-13.

Living and learning with new media: Summary of findings from the digital youth project (2008, November). MacArthur Foundation Reports on Digital Media and Learning. Retrieved on 21 May 2009, from http://www.macfound.org/

Mattar, J. A. (2010). Constructivism and Connectivism in Education Technology: Active, Situated, Authentic, Experiential, and Anchored Learning. Retrieved on 21 July 2011 from http://www.joaomattar.com/ Constructivism\%20and\%20Connectivism\%20 in\%20Education\%20Technology.pdf

McBride, M. F. (2012). Reconsidering information literacy in the 21st century: The redesign of an information literacy class. Journal of Educational Technology Systems, 40(3), 287-300.

McWilliam, E. \& Haukka, S. (2008). Educating the creative workforce: New directions for twenty-first century schooling. British Educational Research Journal, 34(5), 651666. 
Muñoz, C.L. \& Towner, T. L. (2009). Opening Facebook: How to use Facebook in the college classroom. Paper presented at the Society for Information Technology and Teacher Education Conference in Charleston, South Carolina: USA. Retrieved on 10 April 2010, from http://www46.homepage.villanova.edu/john.immerwahr/TP101/ Facebook.pdf

Palloff, R. M. \& Pratt, K. (2007). Building online learning communities: Effective strategies for the virtual classroom (2nd ed.). San Francisco: John Willey \& Sons.

Ravenscroft, A. (2011). Dialogue and connectivism: A new approach to understanding and promoting dialogue-rich networked learning. International Review of Research in Open and Distance Learning, 12(3), 139-160.

Rousseau, J. J. (2007). Historical case study of the Supernet consortium: Investigating change management and the concepts of Connectivism and distributed professional learning communities. Dissertation Abstracts International, 234. (UMI No. 3273647)

Siemens, G. (2004a). Connectivism: A learning theory for the digital age. Retrieved on 14 June 2010 from http://www.elearnspace.org/Articles/connectivism.htm

Siemens, G. (2004b). Connectivism: A learning theory for the digital age. Retrieved on 14 September 2008 from http://www.connectivism.ca

Siemens, G. (2006). Connectivism: Learning and knowledge today. Paper presented at Global Summit 2006: Technology Connected Features, Sydney, Australia. Retrieved on 14 May 2011 from http://www.educationau.edu.au/sites/default/files/gs2006_ siemens.pdf

Siemens, G. \& Tittenberger, P. (2009). Handbook for emerging technologies for learning. Retrieved on 25 July 2011 from http://umanitoba.ca/ learning_technologies/ cetl/HETL.pdf

Sims, R. (2008). Rethinking (e)learning: a manifesto for connected generations. Distance Education, 29(2), 153-164.

Starkey, L. (2010). Teachers' pedagogical reasoning and action in the digital age. Teachers and Teaching: Theory and Practice, 16(2), 233-244.

Thomas, H. (2010). Learning spaces, learning environments and the dis'placement' of learning. British Journal of Educational Technology, 41(3), 502-51.

Tracey, R. (2009). Instructivism, constructivism or connectivism?. Training \& Development in Australia, 36(6), 8-9.

Tu, C.-H., Sujo-Montes, L. E., Yen, C.-J., Chan, J.-Y. \& Blocher, J. M. (2012). The integration of personal learning environments \& open network learning environments. TechTrends, 56(3), 13-19.

Wan, M. H. W. H., Mohd, N. A. R., Zinatul, A. Z., Wan, K. M. \& Noor, I. Y. (2012). A method for finding investor through internet marketing strategy. Australian Journal of Basic and Applied Sciences, 5(12), 1841-1849.

Williams, M. (2008, February). Connectivism from design. Retrieved on 11 November 2009 from http://design.test.olt.ubc.ca/Connectivism 
Williams, R., Karousou, R. \& Mackness, J. (2011). Emergent learning and learning ecologies in Web 2.0. International Review of Research in Open and Distance Learning, 12(3), 39-59.

Correspondence: Hasan Tinmaz, Faculty of Economics and Administrative Sciences, Istanbul Kultur University, Atakoy Campus, Bakırkoy, Istanbul, Turkey 